NETTO et al., v(11), no 11, p. 2266-2272 , JUN, 2013.

Rev. Elet. em Gestão, Educação e Tecnologia Ambiental (e-ISSN: 2236-1170)

\title{
OFICINAS AMBIENTAIS COMO ESPAÇO DE CONSTRUÇÃO DA CONSCIÊNCIA AMBIENTAL
}

\author{
WORKSHOPS ENVIRONMENTAL SPACE AS CONSTRUCTION OF ENVIRONMENTAL AWARENESS
}

\author{
Tatiane Almeida Netto', Letícia Fátima de Azevedo², Mirele Milani da Silva³, \\ Letícia Paludo Vargas ${ }^{4}$, Clayton Hillig ${ }^{5}$
}

\begin{abstract}
1'Mestranda do Programa de Pós Graduação em Extensão Rural - PPGExR/UFSM. Email: tatinetto@yahoo.com.br ${ }^{2}$ Mestranda do Programa de Pós Graduação em Extensão Rural - PPGExR/UFSM. Email: letiazevedo@hotmail.com ${ }^{3}$ Mestranda do Programa de Pós Graduação em Extensão Rural - PPGExR/UFSM. Email: mireleturismo@yahoo.com.br ${ }^{4}$ Mestranda do Programa de Pós Graduação em Extensão Rural - PPGExR/UFSM. Email: leticiavargas@zootecnista.com.br

${ }^{5}$ Docente do Programa de Pós Graduação em Extensão Rural - PPGExR/UFSM. Email: hilig@smail.ufsm.br
\end{abstract}

http://dx.doi.org/10.5902/223611708647

\section{RESUMO}

As oficinas ambientais atuam como um processo de conscientização e conhecimento da problemática em questão, neste trabalho será analisado as oficinas ambientais desenvolvidas, nos anos de 2011 e 2012, junto ao Projeto Arquitetos do Saber, com estudantes da escola rural Dr. Honorato de Souza Santos. A metodologia utilizada para o desenvolvimento desse estudo foi a pesquisa participante, apoiada pela instituição, inserido no Projeto Institucional UFSM/Tecnologias de Inclusão social: cidadania, educação ambiental e agroecologia. $O$ objetivo do estudo é analisar a prática das oficinas ambientais como processo de reflexão-ação por parte dos estudantes para a tomada da consciência e preservação ambiental. Os resultados alcançados permitiram aos alunos a tomada de consciência em relação à preservação e conservação do meio ambiente e aproximação e interação entre o universo escolar e o meio acadêmico. Conclui-se que as oficinas cumprem o propósito de despertar a percepção ambiental e promover um processo de conscientização dos alunos do ensino fundamental da escola Dr. Honorato de Souza Santos/Cachoeira do Sul-RS.

Palavras-chave: cidadania, meio ambiente, reflexão- ação, rural

\begin{abstract}
The environmental workshops act as a process of awareness and knowledge of the issue in this work will be analyzed environmental workshops developed in the years 2011 and 2012, with the design of Knowledge Architects with students from rural school Dr. Honorato de Souza Santos. The methodology used for this study was to develop participatory research, supported by the institution, inserted in Institutional Project UFSM/Technology Social inclusion: citizenship, environmental education and agroecology. The objective of the study is to analyze the practice of environmental workshops as reflection-action process by students for making awareness and environmental preservation. The results allowed the students the awareness regarding the preservation and conservation of the environment and proximity and interaction between the school and the academic universe. We conclude that the workshops fulfill the purpose of raising environmental awareness and promoting a process of awareness of elementary students from school Dr. Honorato de Souza Santos/Cachoeira do Sul-RS.
\end{abstract}

Keywords:_citizenship, environment, reflection-action, rural 
NETTO et al., v(11), no 11, p. 2266-2272 , JUN, 2013.

Rev. Elet. em Gestão, Educação e Tecnologia Ambiental (e-ISSN: 2236-1170)

\section{INTRODUÇÃO}

A escola básica é o espaço para aquisição de habilidades, competências e conhecimentos fundamentais ao exercício da cidadania, pois possibilita a construção da dignidade humana que é o meio para o desenvolvimento sustentável no campo, onde através dela podem ocorrer mudanças no paradigma social (SILVA, 2004).

A escola possui o papel social de transmissão de conhecimento científico, tecnológico, filosófico e cultural, interligados ao mundo de vida dos sujeitos sociais. Saviani (2007) aponta que - Brasil enfrenta problemas na educação básica em decorrência da maneira como é encarada a ciência pela escola, ela deve fazer parte de um contexto social numa compreensão do seu significado social e não apenas a transmissão de conteúdos científicos independentes da sociedade.

A educação deve preparar as novas gerações para aceitar as incertezas e para novas mentalidades capazes de compreender as complexas inter-relações gerar um pensamento aberto às especificidades. Possibilitando a construção e a reconstrução de um processo contínuo de novas leituras e interpretações, um processo dialógico para a construção de uma nova racionalidade e emancipação que permita novas formas e reapropriação do mundo (JACOBI, 2004).

Ao trabalharmos educação ambiental, ainda mais no rural, não se pode desvincular os saberes locais e a cultura presente. Segundo Saviani (2007) não se pode avaliar a escola desconectada da realidade histórico-cultural, ela é integrante e inseparável dos fenômenos sociais, deve ser encarada como um produto da prática social de grupos e de classes o que permite sua transformação, com a mudança das práticas pedagógicas atinge-se a sociedade.

Pode-se fazer uma relação à educação ambiental e a educação popular, tendo em vista que o paradigma da educação popular, referenciado por Paulo Freire, parte-se da educação ambiental como um processo de conscientização do estudante, em relação às parcelas desfavorecidas da sociedade, provocando assim novas percepções e questionamentos sobre seu lugar, tornando possíveis ações no seu comportamento com o meio ambiente.

O conceito de educação popular parte da realidade das camadas sociais, leva em conta o local, a região em que vive o aluno e tem como objetivo primordial a inserção dele no processo educativo, de modo vivo e dinâmico, incluído numa política desenvolvimentista (FREIRE, 2002).

A pesquisa se evidencia nas práticas de oficinas ambientais do Projeto Arquitetos do Saber pelo fato de o mesmo ser desenvolvido junto a uma escola rural - denominada Dr. Honorato de Souza Santos - e utilizar-se dos paradigmas da educação popular e da ciência agroecológica nas atividades de educação ambiental. Também é enfatizado que a comunidade em torno da escola encontra-se em situação vulnerável, de risco ambiental e social, por apresentar-se em região periférica e próxima de um aterro sanitário.

A escola Dr. Honorato de Souza Santos participa do Projeto de Extensão "Arquitetos do Saber" , desde o ano de 2011, o qual é realizado pelo grupo de pesquisa em Extensão Rural Aplicada do Departamento de Educação Agrícola e Extensão Rural do Centro de Ciências Rurais (CCR) da Universidade Federal de Santa Maria/RS (UFSM).

O Projeto Arquitetos do Saber busca integrar a escola e a comunidade escolar, onde os conhecimentos são articulados com o estágio de desenvolvimento econômico social e político da sociedade, de acordo com o estágio atual do desenvolvimento científico e tecnológico e dos seus 
NETTO et al., v(11), no 11, p. 2266-2272 , JUN, 2013.

Rev. Elet. em Gestão, Educação e Tecnologia Ambiental (e-ISSN: 2236-1170)

significados na sociedade moderna.

O objetivo da pesquisa é analisar as práticas das oficinas ambientais junto à escola rural Dr. Honorato de Souza Santos/Cachoeira do Sul-RS, bem como verificar a inserção do processo de percepção e conscientização ambiental nos estudantes.

\section{METODOLOGIA}

Como recurso metodológico, procurou-se desenvolver uma pesquisa participante através das práticas das oficinas ambientais na Escola Estadual de Ensino Fundamental Dr. Honorato de Souza Santos - localidade Passo d' Areia no município de Cachoeira do Sul - RS, nos anos de 2011 e 2012.

Uma pesquisa de caráter exploratório e descritivo a qual aprecia a utilização de diferentes métodos e a abordagem qualitativa para análise dos dados, buscando aprofundar a análise e não apenas conhecer os fatos de forma sumária, para que assim seja possível uma reflexão sobre esta pesquisa. A análise consiste na experiência das práticas ambientais, na ação comunicativa dos sujeitos e diálogos dos estudantes, considerando a expressão de sua cultura, modo de vida, significados atribuídos e valores.

O método que orientou a pesquisa é o dialético crítico e a dialógica freiriana, método este que permite reconhecer o caráter político da pesquisa social, como construção coletiva que parte da realidade dos sujeitos mediando processos de desvendamento através da reflexão. Possibilita olhar, entender, analisar e interpretar a ação comunicativa e a produção de conhecimento acerca desse processo, que, por sua vez, sofrerá outras transformações.

O diálogo é o encontro entre os homens, mediatizados pelo mundo, para designá-lo. Se ao dizer suas palavras, ao chamar ao mundo, os homens o transformam, o diálogo impõe-se como o caminho pelo qual os homens encontram seu significado enquanto homens; o diálogo é, pois, uma necessidade existencial (FREIRE, 1980, p.82 e 83).

A análise de dados, obtidos através das técnicas de observação direta e diário de campo, compreende a discussão da prática dialógica comunicativa na realização das oficinas ambientais, especificamente utilizamos a análise temática que "consiste em descobrir os núcleos de sentido que compõem uma comunicação cuja presença ou frequência signifiquem alguma coisa para o objetivo analítico visado" (MINAYO, 2001).

\section{RESULTADOS E DISCUSSÃO}

Os resultados foram observados a partir da análise temática das práticas de oficinas ambientais desenvolvidas na escola Dr. Honorato de Souza Santos pelo Projeto Arquitetos do Saber. A análise tem ênfase na metodologia utilizada nas práticas e nas temáticas abordadas.

A metodologia utilizada nas oficinas do Projeto Arquitetos do Saber se embasam no conceito de simetria discursiva, desenvolvido pelo Paulo Freire e pela Teoria da Ação Comunicativa desenvolvida por Habermas. As atividades ocorreram através de diálogos, interações entre os alunos, conhecimento partilhado com os alunos e não somente direcionado a 
NETTO et al., v(11), no 11, p. 2266-2272 , JUN, 2013.

Rev. Elet. em Gestão, Educação e Tecnologia Ambiental (e-ISSN: 2236-1170)

eles, priorizando a inserção dos alunos no processo educativo, promovendo a inserção social contextualizada com os temas propostos (GONÇALVES, 1999; FREIRE, 1979).

No primeiro ano (2011) as atividades de práticas ambientais se concentraram no tema meio ambiente (conservação e preservação); água; fauna e flora e resíduos. Já no segundo ano de execução (2012), focaram-se os estudos no corpo humano, onde no estímulo à descoberta, ao pensar, ao criar, à experimentação e a aproximação do saber popular introduz os temas das plantas medicinais e da alimentação saudável. Todas as atividades de práticas ambientais promovem a transversalidade ao currículo escolar, abordando tópicos em áreas das disciplinas de ciências, matemática, português, geografia e história.

As atividades de práticas ambientais no ano de 2011 foram realizadas na escola e também por meio de saídas de estudo na Mostra de Biologia e no Departamento de Defesa Fitossanitária da Universidade Federal de Santa Maria/UFSM e no Criadouro Conservacionista São Braz/Santa Maria. Esses momentos de estudo e visitas temáticas permitem a reflexão por parte dos estudantes, a percepção e constatação do meio, uma nova vivência, passam a perceber a realidade histórico social, que pode ser transformada por eles através do empoderamento de conhecimento.

As oficinas e seminários realizados na escola, durante o primeiro ano de execução do projeto, contaram com a participação ativa dos alunos, onde buscou a participação dos seus pais nas visitas de estudo, bem como dos professores da escola. Para tanto, foram utilizados recursos audiovisuais (filmes educativos e power point), cartilhas educativas e dinâmicas participativas referentes ao tema (gincana, jogos, hora do conto...).

Para desenvolvermos a educação precisamos de metodologias participativas, da hermenêutica, da pedagogia da complexidade voltada para a problematização dos diferentes sentidos, interesses e forças sociais que se organizam em torno das questões ambientais. Ao reinterpretar as interpretações vigentes, esta prática educativa abre um campo de novas possibilidades de compreensão e auto compreensão, no sentido do reposicionamento e engajamento dos sujeitos na problemática ambiental (CARVALHO, 2003).

Na temática do meio ambiente/conservação e preservação o grupo de monitores utilizou como recurso metodológico a dinâmica "retrato da vida", que tinha como propósito o reconhecimento da comunidade, da realidade local. Educar é saber "ler" o mundo, conhecê-lo para transformá-lo e ao transformá-lo, conhecê-lo (GADOTTI, 2003). A técnica permitiu aos alunos se expressarem através de símbolos e desenhos. Através da metodologia utilizada verificou-se a preocupação constante com o reconhecimento da localidade, do espaço e do diálogo como forma de comunicação e apropriação do conhecimento.

Também se observou no primeiro ano que as metodologias utilizadas e as temáticas nas oficinas de água, fauna, flora e resíduos priorizavam a experimentação e a vivência como forma de apropriação dos conhecimentos, o que permitiu uma interação com o mundo de vida dos estudantes e sua realidade rural.

Na temática de água os monitores utilizaram recursos metodológicos como a dinâmica de formação da chuva, onde os estudantes através da experimentação observavam as fases da água e o processo de formação da mesma, fazendo o processo de transversalidade ao currículo escolar na disciplina de ciências. Também nessa temática, observou-se através de uma dinâmica sobre a água, por meio de um pequeno exercício de visualização, que embora exista muita água no 
NETTO et al., v(11), no 11, p. 2266-2272 , JUN, 2013.

Rev. Elet. em Gestão, Educação e Tecnologia Ambiental (e-ISSN: 2236-1170)

planeta, não significa que ela seja acessível, suficiente e boa para o consumo. Toda a experiência vivenciada no contexto das práticas ambientais durante o projeto, evidencia o processo de ensino aprendizagem embasada a partir da realidade dos estudantes e ensina a partir da linguagem e temas geradores do cotidiano deles.

As metodologias e as temáticas utilizadas preocupam-se com o contexto, as realidades e as necessidades de uma escola rural. A diferenciação entre a escola rural e urbana é prevista na formulação das diretrizes da educação. A Lei de Diretrizes e Bases da Educação Nacional (LDB) promove a desvinculação da escola rural e urbana, exigindo um planejamento interligado à vida rural e uma educação com dimensões sócio-políticas e culturais com base na cidadania e na prática social (BRASIL/MEC, LDB 9.394/96).

Ao desenvolver as oficinas em escola rural depara-se com a questão da educação do campo. É nesse sentido que se torna imprescindível expandir as ações não somente para uma educação desenvolvida junto à comunidade rural, mas uma educação que elucide as especificidades do campo, dos seus sujeitos e tendo como propósito o incentivo ao resgate dos valores culturais, de suas práticas de vida, para assim, desenvolver a cidadania. Segundo Caldart (2004), podemos compreender a educação do campo como perspectiva de transformação social.

"[...] superação: projeto/utopia: projeção de uma outra concepção de campo, de sociedade, de relação campo e cidade, de educação, de escola. Perspectiva de transformação social e de emancipação humana" (CALDART, 2004).

No segundo ano de execução das atividades de prática ambientais a temática principal das oficinas tem como foco o saber popular referente às plantas medicinais, onde buscou-se um resgate nas famílias, tradições e cultura local.

A partir das plantas levadas pelos alunos, foi trabalhado o sentido e a importância das plantas medicinais, do emprego do nome científico, os usos, contraindicações e cuidados com as dosagens, nomes populares, origem, habitat, etc. Para a elaboração das oficinas também se utilizaram as técnicas visuais com imagens de plantas medicinais, chás industrializados e dados da literatura especializada. Algumas espécies com morfologia ou nomes populares semelhantes foram trabalhadas a partir de suas principais diferenças e para isso usou-se além de fotos, exemplares vivos, realçando as diferenças morfológicas e organolépticas (cor, cheiro, textura). Ao final de cada atividade os alunos fizeram desenhos e textos sobre as plantas estudadas. Os desenhos serão utilizados na ilustração de uma cartilha com informações sobre as plantas medicinais estudadas para uso da comunidade escolar.

O processo de ensino aprendizagem desenvolvido, no momento das oficinas, é encarado como ato de conhecimento e transformação social, tendo como característica principal a utilização do saber como matéria prima para o ensino. Além disso, visa desenvolver a capacidade de observação e pesquisa do aluno, estimular seu senso crítico em relação às questões ambientais, despertar a consciência da importância da preservação do meio ambiente, do respeito à natureza, incentivar a participação e o trabalho na busca de soluções para a melhoria da qualidade de vida de todos. 
NETTO et al., v(11), no 11, p. 2266-2272 , JUN, 2013.

Rev. Elet. em Gestão, Educação e Tecnologia Ambiental (e-ISSN: 2236-1170)

\section{CONCLUSÕES}

Ao analisar as práticas de educação ambiental junto ao Projeto Arquitetos do Saber, observa-se que os alunos através das metodologias e temáticas centradas na conscientização, mudança de comportamento, desenvolvimento de competências, capacidade de avaliação e participação alcançam a tomada de consciência quanto ao saber-fazer.

A conscientização ambiental em relação à preservação e conservação do meio ambiente, assim como, a aproximação e interação entre o universo escolar e o meio acadêmico são obtidas através das vivências nas instituições públicas e privadas como os laboratórios na UFSM e a visita ao Criadouro Conservacionista São Braz.

O projeto propôs através das práticas ambientais, fundamentadas no diálogo e troca de experiências que os alunos percebam e compreendam o seu meio, busquem a autonomia no agir e pensar.

Por fim, acredita-se que nas práticas de educação ambiental ocorre um incentivo para a multiplicação dos temas abordados (água, meio ambiente (preservação e conservação), fauna e flora, resíduos, alimentação saudável e plantas medicinais) contribuindo no desenvolvimento da responsabilidade social e ambiental. As oficinas trazem sua contribuição para a construção de um ambiente educativo que considere a relação com o meio ambiente, a cultura e os saberes próprios dos alunos. O projeto utilizou na metodologia das oficinas o conceito de educação ambiental na construção do comprometimento socioambiental almejado pela escola rural.

\section{AGRADECIMENTOS}

À Capes (Edital Novos Talentos) pelo apoio financeiro para execução do Projeto Arquitetos do Saber.

\section{REFERÊNCIAS BIBLIOGRÁFICAS}

BRASIL. Lei no 9.394, de 20 de dezembro de 1996. Lei de Diretrizes e Bases da Educação Nacional, Brasília, DF, 20 dez. 1996. Disponível em: <http://portal.mec.gov.br/arquivos/pdf/ldb.pdf>. Acesso em: 21 jul. 2012.

CALDART, R. Por uma educação do campo: traços de uma identidade em construção. In: ARROYO, M. G.; CALDART, R.; MOLINA, M (Orgs.). Por uma educação do campo. Petrópolis: Vozes, 2004.

CARVALHO, I. Os sentidos do ambiental: a contribuição da hermenêutica à pedagogia da complexidade. In: LEFF, E. (Coord.). A Complexidade Ambiental. São Paulo: Cortez Editora, 2003.

FREIRE, P. Pedagogia da autonomia: saberes necessários à prática educativa. Col. Leitura, Rio de Janeiro, Paz e Terra, 2002.

Conscientização: teoria e prática da libertação - uma introdução ao pensamento de Paulo Freire. 3. ed. São Paulo: Moraes, 1980.

Educação como prática de liberdade. 17. ed. Rio de Janeiro: Paz e Terra, 1979. 


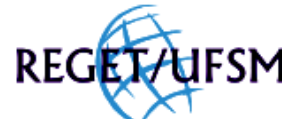

NETTO et al., v(11), no 11, p. 2266-2272 , JUN, 2013.

Rev. Elet. em Gestão, Educação e Tecnologia Ambiental (e-ISSN: 2236-1170)

GADOTTI, M. Saber aprender: um olhar sobre Paulo Freire e as perspectivas atuais da educação. In: LINHARES, C.; TRINDADE, M. N. (Orgs.). Compartilhando o mundo com Paulo Freire. São Paulo: Cortez, 2003.

GONÇALVES, M. A. S. Teoria da ação comunicativa de Habermas: Possibilidades de uma ação educativa de cunho interdisciplinar na escola. Educação \& Sociedade, ano XX, n. 66, 1999.

JACOBI, P. Educação e meio ambiente - transformando as práticas. Revista Brasileira de Educação Ambiental/Rede Brasileira de Educação Ambiental. Brasília: Rede Brasileira de Educação Ambiental, 2004.

MINAYO, M. C. S. Pesquisa social: teoria, método e criatividade. Petrópolis: Editora Vozes, 2001.

SILVA, M. S. Educação do Campo e Desenvolvimento: uma relação construída ao longo da história. 2004. Disponível em: <http://www.contag.org.br/imagens/f299Educacao do Campo e Desenvolvimento Sustentavel.pdf >. Acesso em: 10 dez. 2012.

SAVIANI, D. Trabalho e educação: fundamentos ontológicos e históricos. Revista Brasileira de Educação, v. 12, n. 34, 2007. 